\title{
Hidratação e desidratação de óxido de magnésio em concretos refratários
}

\section{(Magnesia sinter hydration-dehydration behavior in refractory castables)}

\author{
R. Salomão ${ }^{1}$, V. C. Pandolfelli \\ Departamento de Engenharia de Materiais, Universidade Federal de S. Carlos \\ Rod. Washington Luiz, km 235, C.P. 676, S. Carlos, SP 13565-905 \\ rflslm@gmail.com,vicpando@power.ufscar.br
}

\begin{abstract}
Resumo
Óxido de magnésio (MgO) rapidamente reage com água quando exposto a umidade ou durante a mistura de concretos refratários, gerando uma camada de hidróxido de magnésio, $\mathrm{Mg}(\mathrm{OH})_{2}$, na superfície das partículas. Durante a secagem desses materiais entre $350{ }^{\circ} \mathrm{C}$ e $600{ }^{\circ} \mathrm{C}$ essa camada se decompõe, gerando superfícies de $\mathrm{MgO}$ altamente reativas. O modo como esse processo afeta as propriedades de concretos refratários não foi descrito de modo satisfatório na literatura. Neste trabalho, suspensões aquosas de sínter de $\mathrm{MgO}$ termicamente tratado $\left(110-900{ }^{\circ} \mathrm{C}\right)$ foram preparadas. O efeito da temperatura de calcinação em sua reatividade foi avaliado por meio da técnica de medida de expansão volumétrica aparente. Com base nesses resultados, o comportamento de secagem de concretos refratários contendo MgO foi relacionado com medidas de resistência mecânica e porosidade. Também foram investigados os danos causados pela re-hidratação do $\mathrm{MgO}$ após a exposição dos concretos secos à umidade ambiente.

Palavras-chave: concretos refratários, óxido de magnésio, hidróxido de magnésio, hidratação, desidratação, calcinação.
\end{abstract}

\begin{abstract}
Magnesia (MgO) easily reacts with water when exposed to humidity or along the mixing of refractory castables, resulting a $\mathrm{Mg}(\mathrm{OH})_{2}$ coating layer on its particle surface. During castables dewatering above $350{ }^{\circ} \mathrm{C}$ this coating begins to decompose, generating porosity and a highly reactive magnesia. Despite the abundant literature concerning magnesia hydration-dehydration mechanisms, few studies were related to refractory. In the present work, aqueous suspensions of thermally treated magnesia sinter were prepared and the influence of the calcination temperature on magnesia reactivity was estimated by the apparent volumetric expansion measurements. Based on these results, the drying behavior of magnesia sinter containing castables was related to mechanical strength and porosity measurements. The effects of re-hydration damages caused by humidity exposition after drying was also investigated.
\end{abstract}

Keywords: magnesia, hydration, calcination, dehydration.

\section{INTRODUÇÃO}

A reação de hidratação do óxido de magnésio (MgO) ou magnésia é um dos principais fatores limitantes à sua utilização em concretos refratários [1-3]. Dois principais efeitos colaterais podem ser encontrados na literatura. O primeiro, conhecido como expansão volumétrica aparente (EVA) [4], está relacionado à expansão volumétrica da ordem de três vezes que acompanha a hidratação do $\mathrm{MgO}$ (equação A)

$$
\mathrm{MgO}+\mathrm{H}_{2} \mathrm{O} \rightarrow \mathrm{Mg}(\mathrm{OH})_{2}
$$

Essa expansão é causada pela diferença de densidade entre óxido $\left(\rho_{\mathrm{MgO}}=3,5 \mathrm{~g} / \mathrm{cm}^{3}\right)$ e hidróxido de magnésio $\left(\rho_{\mathrm{Mg}(\mathrm{OH}) 2}=2,4 \mathrm{~g} / \mathrm{cm}^{3}\right)[5-8]$, também conhecido como

${ }^{1}$ Endereço atual: Centro de Engenharia, Modelagem e Ciências Sociais Aplicadas, Universidade Federal do ABC, Rua da Catequese 242, Santo André, SP 09090-400. brucita. Devido à estrutura rígida e compacta dos concretos, essa expansão não consegue ser convenientemente acomodada na porosidade e pode facilmente gerar tensões de compressão capazes de romper material. O segundo efeito é o objeto de estudo deste trabalho e está relacionado ao uso de partículas de MgO parcialmente hidratadas em formulações de concreto refratário e às suas conseqüências no programa de secagem.

Partículas finas de $\mathrm{MgO}$ rapidamente reagem com a umidade do ar, durante o período de estocagem [9], ou com água, durante a mistura e cura dos concretos, desenvolvendo uma camada fina e micro-trincada de brucita em sua superfície (Fig. 1a) [5, 8]. Essa camada de hidróxido pode atuar como uma barreira à difusão da água nos estágios iniciais da hidratação [8] e, em determinadas condições de temperatura e umidade, pode interromper totalmente a reação $[1,8,9]$.

Quando esse tipo de partícula parcialmente hidratado é adicionado às formulações de concreto refratário, a camada de $\mathrm{Mg}(\mathrm{OH})_{2}$ é preservada durante a cura e enrijecimento do material e sua baixa reatividade reduz consideravelmente 


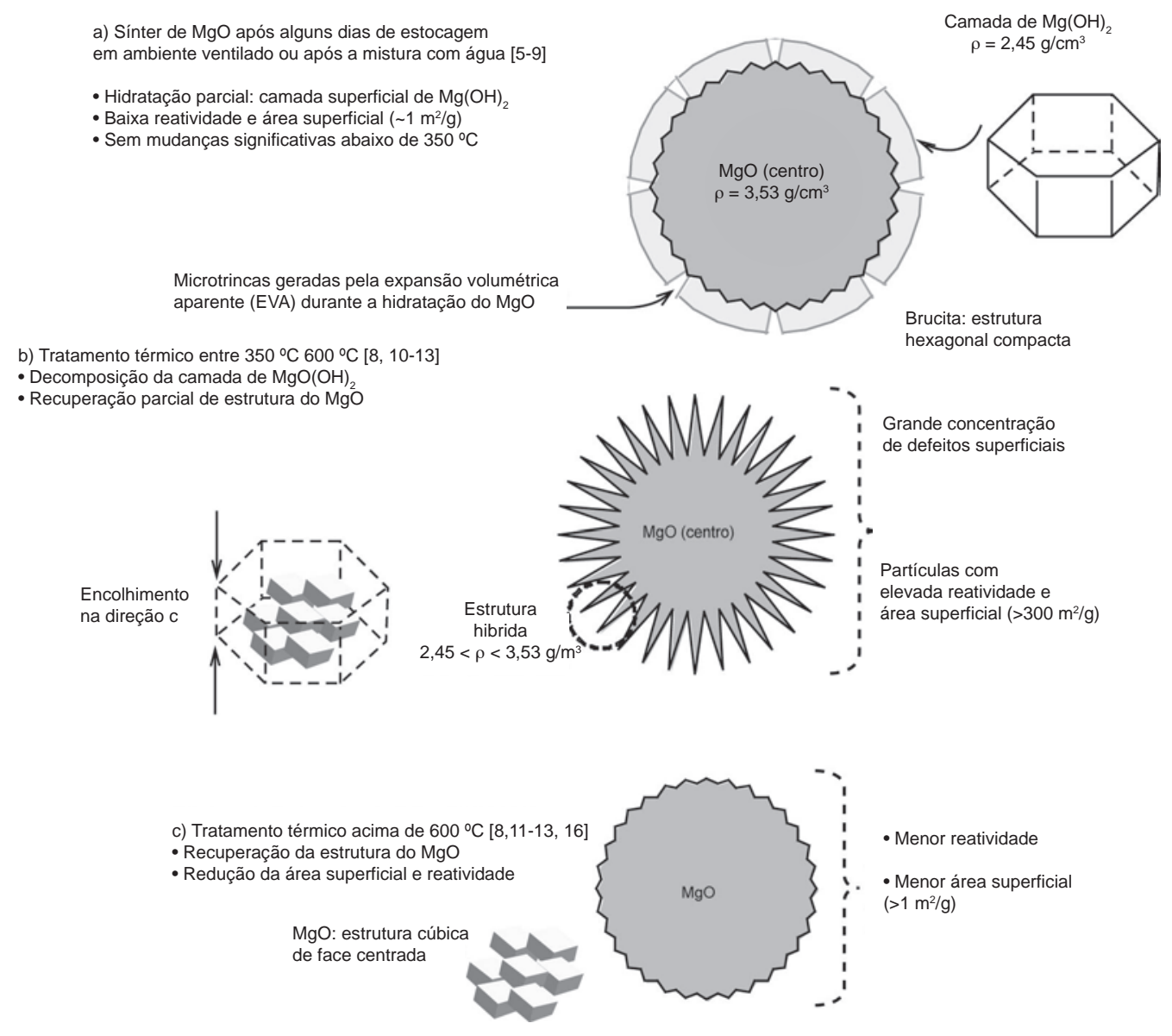

Figura 1: Mecanismo de decomposição do $\mathrm{Mg}(\mathrm{OH})_{2}$ : a) partícula de $\mathrm{MgO}$ parcialmente hidratada após exposição à água ou umidade; b) após calcinação em temperatura intermediárias (350-600 $\left.{ }^{\circ} \mathrm{C}\right)$ e c) após calcinação acima de $600{ }^{\circ} \mathrm{C}$.

[Figure 1: $\mathrm{Mg}(\mathrm{OH})_{2}$ decomposition mechanism: a) partially hydrated $\mathrm{MgO}$ after humidity or water exposition; b) after calcination at intermediate temperatures $\left(350-600^{\circ} \mathrm{C}\right.$ ) and c) after calcination above $600{ }^{\circ} \mathrm{C}$.]

os problemas relacionados à hidratação do MgO. No entanto, durante o primeiro aquecimento do concreto, entre 350-600 ${ }^{\circ} \mathrm{C}$, o $\mathrm{Mg}(\mathrm{OH})_{2}$ começa a se decompor, segundo a reação:

$$
\mathrm{Mg}(\mathrm{OH})_{2} \rightarrow \mathrm{MgO}+\mathrm{H}_{2} \mathrm{O}
$$

Nessa faixa de temperatura, a estrutura do $\mathrm{Mg}(\mathrm{OH})_{2}$ tem uma significativa contração volumétrica, gerando porosidade da estrutura do concreto e tornando-se altamente reativa devido à elevada área superficial (Fig. 1b) [8, 10-14]. Entre as possíveis conseqüências desse efeito, pode-se citar a redução de resistência termomecânica, o aumento da susceptibilidade à umidade e o aumento da penetração de escória e velocidade de corrosão.

Com o objetivo de avaliar a extensão desse tipo de dano em concretos refratários contendo MgO, o presente trabalho foi dividido em duas seções. Inicialmente, foi investigado o efeito da temperatura de calcinação $\left(110-900{ }^{\circ} \mathrm{C}\right)$ na reatividade do sínter de MgO parcialmente hidratado, utilizando suspensões aquosas. Os resultados obtidos foram, então, relacionados aos efeitos de diferentes temperaturas de secagem e exposição à umidade observados nos concretos refratários contendo MgO.

\section{MATERIAIS E MÉTODOS}

Sínter de MgO (contendo 95 \%peso de MgO, Tabela I) foi inicialmente estocado em ambiente ventilado $\left(25^{\circ} \mathrm{C}\right.$ e $50 \%$ de umidade relativa), durante 7 dias e, em seguida, tratado termicamente em diferentes temperaturas $(50,110,350$, 400, 500, 600, 700, 800 e $900{ }^{\circ} \mathrm{C}$ ) por $5 \mathrm{~h}$, com uma taxa de aquecimento de $10^{\circ} \mathrm{C} / \mathrm{min}$.

Durante a calcinação, a cinética de desidratação do sínter parcialmente hidratado e de um hidróxido de magnésio de alta pureza (Synth, Brasil) de granulometria similar foi acompanhada por meio de termogravimetria e com o uso dos parâmetros $\mathrm{W}_{\mathrm{D}}$, referente à perda de massa cumulativa, $\mathrm{e}$ $\mathrm{dW}_{\mathrm{D}} / \mathrm{dt}$, sua variação com o tempo, definidos como

$$
\mathrm{W}_{\mathrm{D}}(\%)=100 \times\left(\mathrm{M}_{0}-\mathrm{M}\right) / \mathrm{M}_{0}
$$


Tabela I - Matérias primas utilizadas.

[Table I - Raw materials tested.]

\begin{tabular}{c|cccc}
\hline & \multicolumn{4}{|c}{ Matérias primas } \\
\hline $\begin{array}{c}\text { Características } \\
\text { físico-químicas }\end{array}$ & $\begin{array}{c}\text { Sínter de } \mathrm{MgO} \\
\text { (como recebido) } *\end{array}$ & $\mathrm{Mg}(\mathrm{OH})_{2} * *$ & $\begin{array}{c}\text { Cimento de aluminato } \\
\text { de cálcio (CA14M) *** }\end{array}$ & $\begin{array}{c}\text { Alumina calcinada } \\
\text { (Esy Pump 1000) }\end{array}$ \\
\hline Composição & $95 \% \mathrm{p}$ & $99,8 \% \mathrm{p}$ & $70 \% \mathrm{p} \mathrm{Al}_{2} \mathrm{O}_{3} /$ & $99,5 \% \mathrm{p}$ \\
Densidade $\left(\mathrm{g} / \mathrm{cm}^{3}\right)$ & $\mathrm{MgO}$ & $\mathrm{Mg}(\mathrm{OH})_{2}{ }^{\star}$ & $30 \% \mathrm{p} \mathrm{CaO}$ & $\mathrm{Al}_{2} \mathrm{O}_{3}{ }^{\star}$ \\
Área superficial $\left(\mathrm{m}^{2} / \mathrm{g}\right)$ & 3,5 & 2,4 & 2,9 & 3,9 \\
Tamanho de partícula $\left(\mathrm{D}_{90}, \mu \mathrm{m}\right)$ & 1,1 & 10 & 1,3 & 3,3 \\
\end{tabular}

* Magnesita S.A. (Brasil); ** Synth (Brasil) ;*** Almatis (EUA); A Valores típicos.

$$
\left(\mathrm{dW}_{\mathrm{D}} / \mathrm{dt}\right)_{\mathrm{i}}=\left(\mathrm{W}_{\mathrm{i}+10}-\mathrm{W}_{\mathrm{i}-10}\right) /\left(\mathrm{t}_{\mathrm{i}+10}-\mathrm{t}_{\mathrm{i}-10}\right)
$$

onde $\mathrm{M}_{0}$ é a massa da amostra no início do teste e M é a massa registrada em um determinado tempo $t_{i}$ durante o aquecimento [15]. Após esse tratamento térmico, suspensões aquosas foram preparadas com os diversos sínteres (80\%peso de sínter, 10\%peso de cimento de aluminato de cálcio CA14M e $10 \%$ peso de água) e colocadas em moldes cilíndricos de $70 \mathrm{~mm}$ de diâmetro por $70 \mathrm{~mm}$ de altura, especificamente desenvolvidos para acompanhar a expansão volumétrica aparente (EVA) gerada pela hidratação do MgO [4]. Maiores detalhes da formulação são mostrados na Tabela IIa.

A EVA é calculada com as equações E e F, considerandose o volume inicial das amostras como referência:

$$
\begin{aligned}
& V_{i}=(1 / 4) \times H_{i} \times \pi \times\left(D_{i}-2 e\right)^{2} \\
& \operatorname{AVE}(\%)=100 \times\left(V_{E}-V_{0}\right) / V_{0}
\end{aligned}
$$

Na equação D, utilizada para calcular o volume das amostras cilíndricas $\left(\mathrm{V}_{\mathrm{i}}\right)$ após um determinado tempo, $\mathrm{H}_{\mathrm{i}}$ é a altura da amostra, $\mathrm{D}_{\mathrm{i}}$ é seu diâmetro e $e$ é a espessura da parede do molde. Para o parâmetro EVA na equação $E, V_{0}$ é o volume inicial da amostra e $V_{E}$ é o volume correspondente após a hidratação e expansão. A descrição detalhada dessa técnica e algumas de suas aplicações podem ser encontradas na referência [4]. As amostras foram mantidas a $50{ }^{\circ} \mathrm{C}$ durante 7 dias em uma câmara climática Vöetsch 2020, com umidade relativa próxima a 100\%. Durante esse período, a EVA foi medida a cada $24 \mathrm{~h}$.

Uma composição de concreto refratário vibrável de alta alumina, contendo 6\%peso de sínter de MgO (Magnesita S.A., Brasil), 6\%peso de cimento de aluminato de cálcio (CA14M, Almatis, EUA), 5,5\%peso de água e 0,2\%peso de fosfato de sódio como dispersante (Synth, Brazil) foi utilizada nos testes. Uma composição sem MgO foi utilizada como referência (o teor de MgO foi substituído por alumina calcinada, de granulometria equivalente). Uma descrição mais detalhada da composição pode ser encontrada em [4]

\begin{tabular}{|c|c|c|}
\hline & a) Suspensões de sínter de $\mathrm{MgO}$ & $\%$ peso \\
\hline \multirow[t]{2}{*}{$\begin{array}{c}\text { Matriz } \\
\left(\mathrm{D}_{\text {Partícula }}<100 \mu \mathrm{m}\right)\end{array}$} & $\begin{array}{c}\text { Sínter de } \mathrm{MgO}(95 \% \text { peso } \mathrm{MgO}) * \text { tratado termicamente }\left(50{ }^{\circ} \mathrm{C}, 110^{\circ} \mathrm{C}, 350^{\circ} \mathrm{C} \text {, }\right. \\
\left.400{ }^{\circ} \mathrm{C}, 500{ }^{\circ} \mathrm{C}, 600^{\circ} \mathrm{C}, 700^{\circ} \mathrm{C}, 800^{\circ} \mathrm{C} \text { e } 900^{\circ} \mathrm{C} \text {, a } 10^{\circ} \mathrm{C} / \mathrm{min}\right) \\
\text { Cimento de aluminato de cálcio }(\mathrm{CA} 14 \mathrm{M})^{* *} \\
\text { Água destilada }\end{array}$ & $\begin{array}{l}80 \\
10 \\
10\end{array}$ \\
\hline & b) Concreto refratário contendo sínter de MgO & \%peso \\
\hline $\begin{array}{c}\text { Matriz } \\
\left(\mathrm{D}_{\text {Particula }}<100 \mu \mathrm{m}\right)\end{array}$ & $\begin{array}{l}\text { Aluminas calcinadas (A1000 e A17)** } \\
\text { Cimento de aluminato de cálcio (CA14M)** } \\
\text { Sínter de } \mathrm{MgO}^{*}\end{array}$ & $\begin{array}{l}3 \\
6 \\
6\end{array}$ \\
\hline $\begin{array}{c}\text { Agregados } \\
\left(\mathrm{D}_{\text {Particula }} \geq 100 \mu \mathrm{m},\right. \\
\left.\mathrm{D}_{\text {Max }}=5,6 \mathrm{~mm}\right)\end{array}$ & Alumina eletrofundida branca $* * *$ & 84,8 \\
\hline Dispersante & Fosfato de sódio $* * * *$ & 0,2 \\
\hline
\end{tabular}

Tabela II - a) Suspensões de sínter de MgO termicamente tratado e b) formulações de concreto refratário estudadas. [Table II - a) Thermally treated MgO sinter suspensions and b) compositions of refractory castables tested.]

* Magnesita S.A. (Brasil); ** Almatis (EUA); *** Elfusa (Brasil); **** Synth (Brasil). 
e na Tabela IIb. A mistura a seco e a adição de água foram feitas em um misturador planetário, por cerca de $10 \mathrm{~min}$.

Após a mistura, as formulações foram moldadas sob vibração em moldes cilíndricos (40 x $40 \mathrm{~mm}$ ) para os testes de hidratação/desidratação. A cura foi feita em uma câmara climática Vöetsch 2020 a $8{ }^{\circ} \mathrm{C}$ por 24 h. Essas condições foram utilizadas para garantir um mínimo de resistência mecânica para a desmoldagem das amostras, sem que o MgO se hidratasse significativamente [4]. Os próximos passos são mostrados na Fig. 2a.

Para avaliar o efeito da temperatura máxima de secagem e da susceptibilidade dos concretos à umidade após a secagem, as amostras foram inicialmente secas em diferentes temperaturas (50-900 ${ }^{\circ} \mathrm{C}$, com uma taxa de aquecimento de $10^{\circ} \mathrm{C} / \mathrm{min}$ ). $\mathrm{O}$ teor de água retirado em cada temperatura foi quantificado pelo parâmetro $W_{\text {DTotal }}$ (\%peso), descrito na Equação G, a seguir [15]. Parte das amostras foi utilizada para medir a resistência mecânica e a porosidade logo após a secagem. A outra parte foi exposta a uma atmosfera saturada de umidade a $50{ }^{\circ} \mathrm{C}$ por 7 dias (o aparato utilizado nesse passo é mostrado na Fig. 2b). Após a exposição à umidade, as amostras foram secas durante $24 \mathrm{~h}$ a $110{ }^{\circ} \mathrm{C}$ para remover a água adsorvida, e tiveram a resistência mecânica e porosidade medidas. Essas amostras também foram re-aquecidas a $900{ }^{\circ} \mathrm{C}$ por $5 \mathrm{~h}$ a $10{ }^{\circ} \mathrm{C} / \mathrm{min}$, para determinar o grau de hidratação do $\mathrm{MgO}$, representado pelo parâmetro $\mathrm{W}_{\mathrm{H}}$ (\%peso, Fig. 4). Nesse caso, os valores de $\mathrm{W}_{\mathrm{H}}$ apontam o aumento da hidratação inicial do cimento e do MgO ocorrido durante a exposição à umidade. Os parâmetros $\mathrm{W}_{\text {DTotal }}$ e $\mathrm{W}_{\mathrm{H}}$ foram calculados usando a Equação F:

$$
\mathrm{W}_{\mathrm{i}}=100 \% \times \frac{\left(\mathrm{M}_{\text {Após tratamento térmico }}-\mathrm{M}_{\text {Antes do tratamento térmico }}\right)}{\mathrm{M}_{\text {Após tratamento térmico }}}
$$

a)

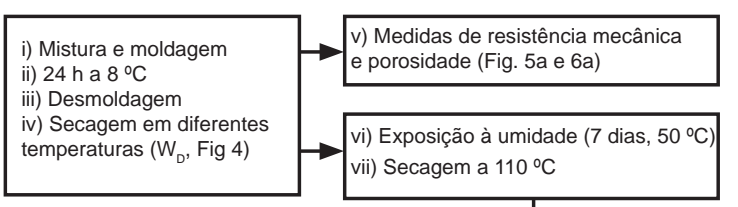

$\downarrow$

vii) Medidas de resistência meânica e porosidade (Fig. 5b e 6b) ix) Secagem a $900^{\circ} \mathrm{C}$ (Wh, Fig. 4)

b)

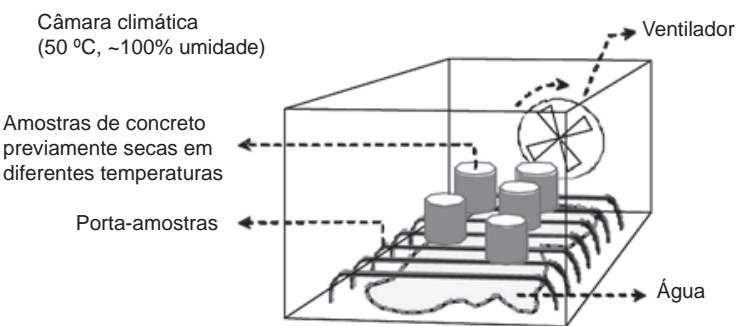

Figura 2: a) Etapas da preparação das amostras e b) aparato utilizado na avaliação da susceptibilidade dos concretos à exposição à umidade (7 dias a $50{ }^{\circ} \mathrm{C}$ ) após secagem.

[Figure 2: a) Steps of the castable processing and b) schematic view of the apparatus employed to evaluate the effect of moisture exposition $\left(50^{\circ} \mathrm{C}, 7\right.$ days) after castables drying]. onde $\mathrm{W}_{\mathrm{i}}$ é um dos parâmetros $\mathrm{W}_{\text {DTotal }}$ ou $\mathrm{W}_{\mathrm{H}}$ e $\mathrm{M}$ são os valores de massa antes ou após os tratamentos térmicos [15].

As medidas de resistência mecânica por compressão diametral foram realizadas segunda a norma ASTM C496-96 em um equipamento MTS TestStar II sob um taxa constante de aplicação de carga de 42 N/s. A porosidade aparente das amostras foi medida pelo método de imersão, utilizando querosene como fluido de imersão. Para cada condição, 5 amostras foram testadas.

\section{RESULTADOS E DISCUSSÃO}

\section{Suspensões de sínter de MgO tratado termicamente}

A Fig. 3 mostra os resultados da termogravimetria do sínter parcialmente hidratado e do $\mathrm{Mg}(\mathrm{OH})_{2}$ de alta pureza (taxa de decomposição ou perda de massa em função da temperatura da amostra) e de EVA para as suspensões preparadas com sínter calcinado em diferentes temperaturas.

Para a amostra de sínter pode-se observar um pequeno pico de perda de massa em $100{ }^{\circ} \mathrm{C}$ referente à remoção de água fisicamente adsorvida, seguido pela decomposição do $\mathrm{Mg}(\mathrm{OH})_{2}$, entre $350{ }^{\circ} \mathrm{C}$ e $635{ }^{\circ} \mathrm{C}$ (temperaturas correspondentes a perdas de massa de $10 \%$ peso e $90 \%$ peso, respectivamente). O composto de alta pureza se decompôs na mesma faixa de temperatura, porém com uma taxa maior. Como os diâmetros médios de partículas são similares, essa diferença foi atribuída principalmente à quantidade de hidróxido presente em cada caso. O composto de alta pureza se decompôs estequiometricamente, perdendo cerca de $30 \%$ de seu peso inicial, enquanto que para o sínter, por outro lado, a perda de massa foi da ordem de $4 \%$, indicando que esse material apresentava um pequeno grau de hidratação antes do tratamento térmico.

Os valores de EVA para as suspensões de sínter também indicam que a reatividade do MgO foi fortemente afetada pela temperatura de tratamento térmico. Os valores máximos de EVA foram observados para as amostras onde o tratamento foi conduzido entre $350-600^{\circ} \mathrm{C}$. Temperaturas inferiores (material parcialmente hidratado, $110{ }^{\circ} \mathrm{C}$ e $300{ }^{\circ} \mathrm{C}$ ) e superiores $\left(700{ }^{\circ} \mathrm{C}, 800{ }^{\circ} \mathrm{C}\right.$ e $900{ }^{\circ} \mathrm{C}$ ) a esse intervalo apresentaram menores valores de EVA.

Como os valores de EVA estão relacionados ao grau de hidratação do MgO (de forma geral: quanto maior o grau de hidratação, maior o valor de EVA gerado) [4], esse parâmetro pode ser utilizado para avaliar a reatividade das amostras após o tratamento térmico. Tratamentos térmicos conduzidos abaixo de $350{ }^{\circ} \mathrm{C}$ não foram suficientes para iniciar a decomposição do $\mathrm{Mg}(\mathrm{OH})_{2}$ e não afetaram significativamente a reatividade do sínter (apenas água fisicamente adsorvida foi liberada) [10, 11]. Por outro lado, para aqueles tratamentos conduzidos entre 350 e $600{ }^{\circ} \mathrm{C}$, um grande aumento na reatividade do $\mathrm{MgO}$ foi verificado. Esse efeito está relacionado à decomposição da camada protetora de $\mathrm{Mg}(\mathrm{OH})_{2}$ na superfície das partículas de $\operatorname{MgO}[8,10,13]$ e à estrutura rica em 


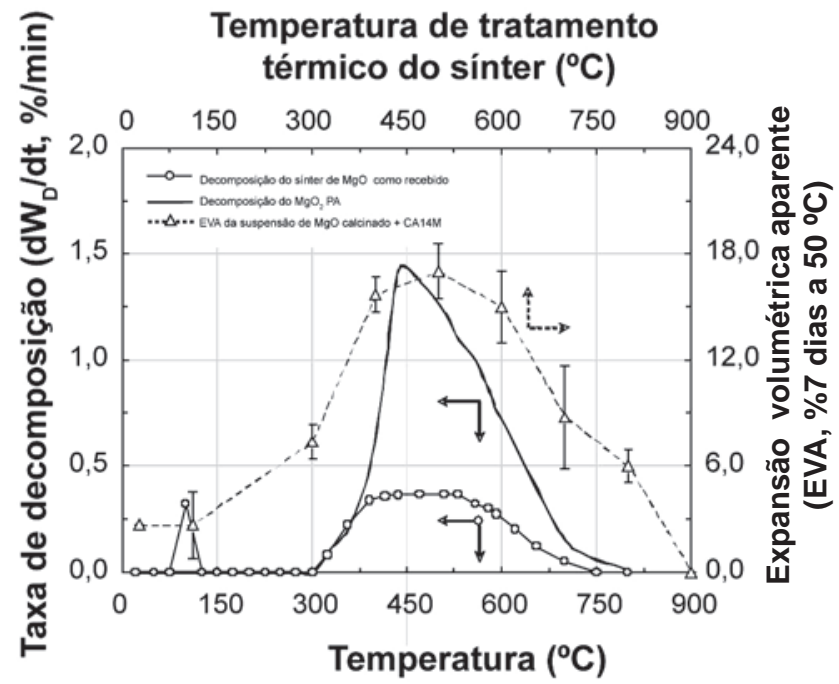

Figura 3: Perfil de taxa de decomposição para sínter de MgO após 7 dias de estocagem em ambiente ventilado e para $\mathrm{Mg}(\mathrm{OH})_{2}$ de alta pureza e expansão volumétrica aparente (EVA) das suspensões de sínter tratado termicamente.

[Figure 3: Drying rate of a 7 days stored sinter and for a highpurity magnesium hydroxides. The apparent volumetric expansion (AVE) results for the thermally treated magnesia sinter suspensions samples are also shown.]

defeitos e de alta área superficial formada (Fig. 1b) [8, 14]. Finalmente, acima de $600{ }^{\circ} \mathrm{C}$ a estrutura original do MgO é reconstruída, reduzindo assim a área superficial das partículas e diminuindo sua reatividade (Fig. 1c) [14, 16].

Esses resultados apresentam uma importante preocupação tecnológica em relação à adição de $\mathrm{MgO}$ em concretos refratários. Se a calcinação do sínter de $\mathrm{MgO}$ (ou de seus precursores, como carbonato de magnésio, $\mathrm{MgCO}_{3}$ ) não for conduzida em condições adequadas, materiais altamente reativos podem ser produzidos, aumentando a probabilidade de danos causados pela EVA [8, 13, 14, 16]. Além disso, dependendo das condições de secagem e aquecimento inicial dos concretos, esses mesmos efeitos podem ocorrer em revestimentos que estejam em contato com a umidade do ambiente. Na próxima seção os resultados apresentados na Fig. 2 serão correlacionados com os efeitos da temperatura máxima de secagem na resistência mecânica, porosidade e susceptibilidade à exposição à umidade de concretos refratários contendo MgO.

\section{Concretos refratários contendo sínter de $\mathrm{MgO}$}

Temperatura de secagem e a resistência mecânica e a porosidade dos concretos

A Fig. 4 mostra o teor de água removido em cada uma das temperaturas de secagem ( $\left.\mathrm{W}_{\text {DTotal }}\right)$; as Figs. 5 e 6 mostram, respectivamente, os efeitos da temperatura de secagem e exposição à umidade na resistência mecânica e porosidade dos concretos.
Pode ser observado na Fig. 4 que quanto maior a temperatura final de secagem, maior a quantidade de água removida. Esse aspecto está de acordo com outros trabalhos [4, 15] e evidencia dois efeitos importantes. a) em temperaturas abaixo de $300{ }^{\circ} \mathrm{C}$ o aumento dos valores de $\mathrm{W}_{\text {DTotal }}$ está relacionado principalmente à retirada de água não combinada da estrutura dos concretos. Quanto maior a temperatura, maior a energia do vapor de água e, conseqüentemente, maior sua tendência a ser liberado para o ambiente [15]; b) acima dessa temperatura, apesar da possibilidade de alguma pequena quantidade de água livre ainda restar, a remoção de água representa principalmente a decomposição de compostos hidratados do cimento e do MgO [4].

Comparados às amostras úmidas, ambas as formulações apresentaram um aumento de resistência mecânica quando as amostras foram secas até $110{ }^{\circ} \mathrm{C}$ (Fig. 5a), enquanto sua porosidade não foi significativamente afetada (Fig. 6a). Entre $110{ }^{\circ} \mathrm{C}$ e $900{ }^{\circ} \mathrm{C}$ uma redução na resistência mecânica e um aumento de porosidade foram observados. Ambos os efeitos foram mais significativos nas amostras contendo MgO. Já para as amostras queimadas a $900{ }^{\circ} \mathrm{C}$, grandes aumentos de resistência mecânica foram observados e seus valores de porosidade se aproximaram daqueles obtidos para as amostras secas a $110{ }^{\circ} \mathrm{C}$.

A dependência da resistência mecânica das amostras em relação à temperatura de secagem pode ser associada aos diferentes efeitos que a remoção da água pode causar na estrutura dos concretos. Em baixas temperaturas $\left(\leq 110{ }^{\circ} \mathrm{C}\right)$, apenas a água não combinada é removida [4, 10, 11]. Esse efeito reduz a distância entre as partículas da matriz, aumentando a resistência mecânica (quando comparada com amostras equivalentes úmidas). Acima dessa temperatura, no entanto, os hidratos do cimento e $\mathrm{MgO}$ começam a se decompor (250-350 ${ }^{\circ} \mathrm{C}$ e $350-630{ }^{\circ} \mathrm{C}$, respectivamente), aumentando a porosidade e reduzindo sua resistência mecânica. Esse efeito é particularmente importante nas amostras contendo MgO,

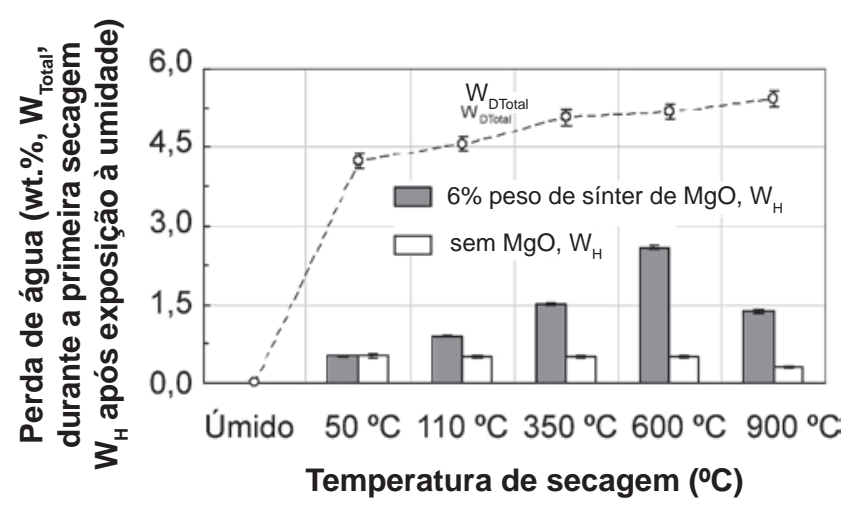

Figura 4: Teor de água removido em cada temperatura máxima de secagem $\left(\mathrm{W}_{\mathrm{DTotal}}\right)$ e massa ganha após exposição à umidade $\left(\mathrm{W}_{\mathrm{H}}\right)$. [Figure 4: Amount of water lost at each maximum drying temperature $\left(W_{\text {DTotal }}\right)$ and gained after humidity exposure $\left(W_{H}\right)$ as measured by heating castable samples up to $900{ }^{\circ} \mathrm{C}$.] 


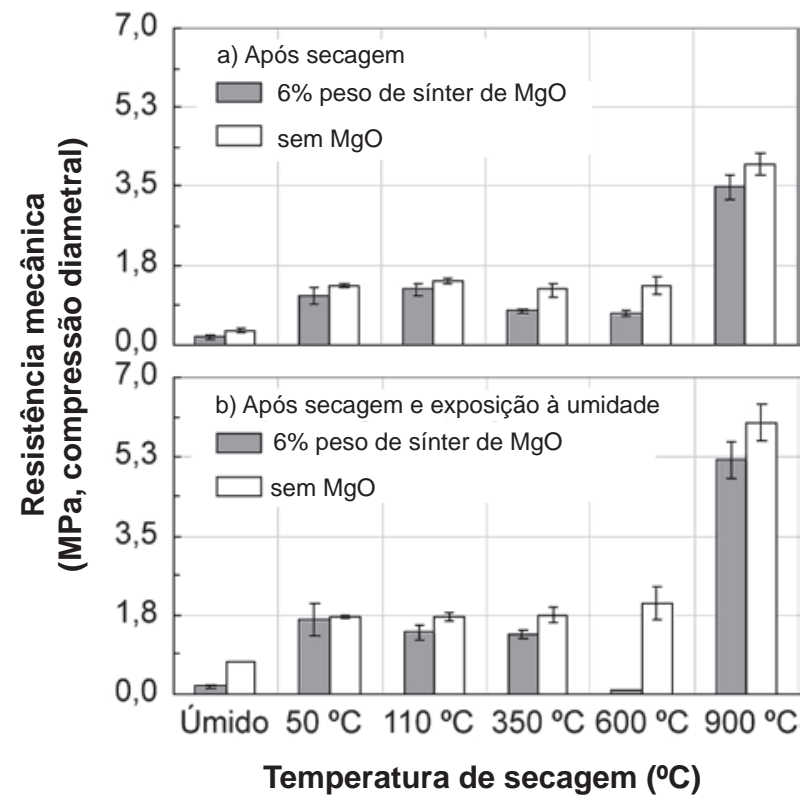

Figura 5: Resistência mecânica das amostras a) após a secagem e b) após secagem e exposição à umidade.

[Figure 5: Samples' mechanical strength a) after drying and b) after drying and exposure to humidity.]

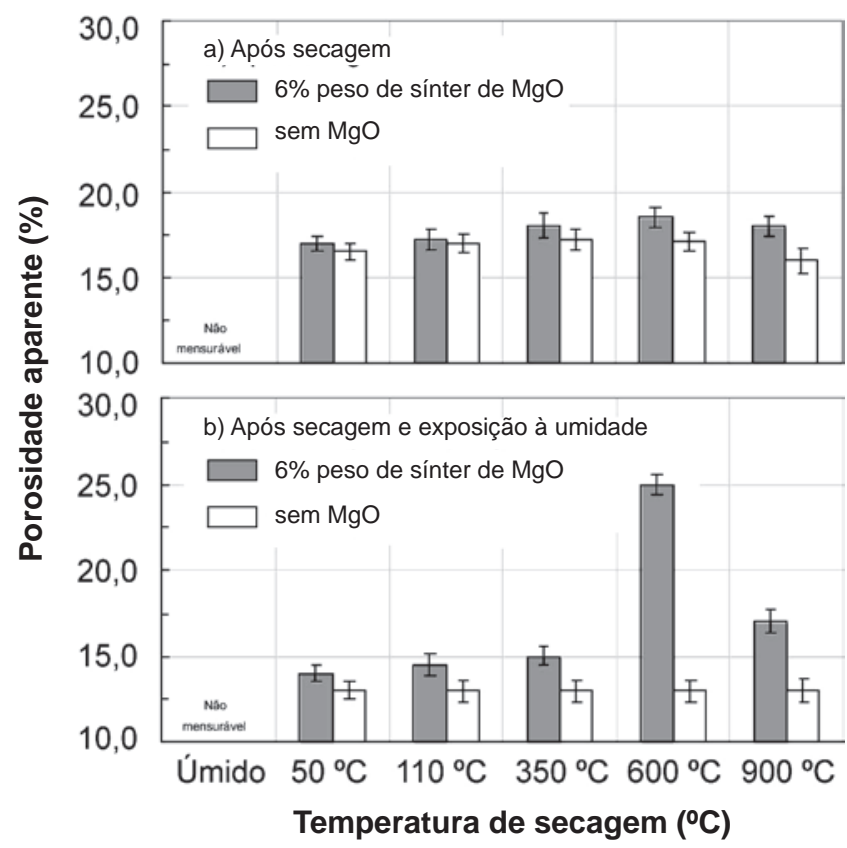

Figura 6: Porosidade das amostras a) após a secagem e b) após secagem e exposição à umidade.

[Figure 6: Samples'porosity a) after drying and b) after drying and exposure to humidity.]

pois, além do fato de elas possuírem ambos os tipos de hidrato e, devido a isso, maior aumento de porosidade, a água liberada pelos hidratos do cimento pode facilmente reagir com o $\mathrm{MgO}$ e gerar danos por meio da EVA. Acima dessas temperaturas, os primeiros efeitos da sinterização podem contribuir para aumentar a resistência mecânica e reduzir a porosidade.
Exposição à umidade após a secagem e a resistência mecânica e a porosidade dos concretos

Os efeitos da exposição à umidade na resistência mecânica e porosidade dos concretos após a secagem podem ser vistos nas Figs. 5b e 6b, respectivamente. Comparando com as amostras testadas logo após a cura (Figs. 5a e 6a), todas as amostras sem $\mathrm{MgO}$ e aquelas contendo $\mathrm{MgO}$ secas até $110^{\circ} \mathrm{C}$ e a $900^{\circ} \mathrm{C}$ apresentaram significativos aumentos de resistência mecânica e redução de porosidade após a exposição à umidade, enquanto aquelas contendo $\mathrm{MgO}$ e secas a $350-600{ }^{\circ} \mathrm{C}$ apresentaram comportamentos opostos. Esses resultados sugerem que, após a secagem, o processo de hidratação do cimento e do MgO possa ser re-iniciado em condições adequadas de umidade e temperatura. Essa hipótese é corroborada pela literatura [17] e pelos resultados de grau de hidratação $\left(\mathrm{W}_{\mathrm{H}}\right)$ após a exposição à umidade (Fig. 4). Pode-se notar que em todas as amostras houve aumentos de massa (na forma de água quimicamente ligada), confirmado a continuação da hidratação do cimento e do MgO devido ao contato com vapor. No entanto, paras as amostras com $\mathrm{MgO}$, os níveis de $\mathrm{W}_{\mathrm{H}}$ foram significativamente maiores e atingiram seus valores máximos para as amostras tratadas termicamente a $350-600{ }^{\circ} \mathrm{C}$. Esses resultados podem ser atribuídos à elevada reatividade química dos materiais tratados nessa faixa de temperatura e à sua grande facilidade de gerar danos por EVA.

Para as amostras contendo $\mathrm{MgO}$ tratados até $110{ }^{\circ} \mathrm{C}$ ou a $900{ }^{\circ} \mathrm{C}$, nenhuma redução de resistência mecânica ou aumento de massa significativos foram observados após exposição à umidade. No primeiro caso (secagem até $110{ }^{\circ} \mathrm{C}$ ), esse comportamento pode ser explicado pela presença da camada protetora de $\mathrm{Mg}(\mathrm{OH})_{2}$ na superfície das partículas de $\mathrm{MgO}$ produzida durante a mistura do concreto e não decomposta durante o tratamento térmico abaixo de $350{ }^{\circ} \mathrm{C}[4,10,11]$. Aquelas tratadas a $900{ }^{\circ} \mathrm{C}$, por outro lado, apresentam grande estabilidade química devido à reconstrução da estrutura original do $\operatorname{MgO}[12,14]$ e aos primeiros estágios da sinterização.

\section{CONCLUSÕES}

Partículas finas de sínter de MgO podem ser parcialmente hidratadas devido ao contato com a umidade da atmosfera, durante o período de armazenamento, ou com água, durante a mistura dos concretos. Em ambos os casos, a camada de hidróxido de magnésio formada na superfície das partículas é preservada durante o enrijecimento dos concretos. Para processos de secagem conduzidos em baixas temperaturas (abaixo de $350^{\circ} \mathrm{C}$ ), ela não é afetada e atua como barreira protetora contra a hidratação do $\mathrm{MgO}$, em caso de novas exposições à umidade. Para aqueles com temperaturas entre $350{ }^{\circ} \mathrm{C}$ e $600{ }^{\circ} \mathrm{C}$, ela é parcialmente decomposta, resultando em um material com elevada reatividade. Devido a estrutura rica em defeitos, porosidade é gerada na estrutura do concreto, reduzindo sua resistência mecânica. Por outro lado, temperaturas acima de $600{ }^{\circ} \mathrm{C}$ permitem que 
a estrutura original do $\mathrm{MgO}$ seja reconstruída, aumentando a resistência à hidratação e a resistência mecânica do material. Aumentos significativos na resistência mecânica e susceptibilidade à umidade dos concretos refratários contendo $\mathrm{MgO}$ podem ser obtidos por meio de modificações simples no programa de secagem desses materiais. Se a temperatura máxima de secagem for limitada a 300 ${ }^{\circ} \mathrm{C}$, grande parte da água (livre e quimicamente ligada) será removida, preservando, ao mesmo tempo, a camada protetora de $\mathrm{Mg}(\mathrm{OH})_{2}$. Nessas condições, não foram observadas modificações significativas nas propriedades dos concretos, mesmo após exposição à umidade. Esse mecanismo pode ser especialmente útil para peças de concreto pré-moldadas e estocadas em ambiente úmido ou para aquelas que entram em contato com produtos à base de água, como tintas, argamassas e concretos projetados, antes do aquecimento até a temperatura de sinterização. Por outro lado, em revestimentos aplicados in situ, o aquecimento deve ser conduzido até pelo menos $900{ }^{\circ} \mathrm{C}$ para garantir a reconstrução da estrutura do $\mathrm{MgO}$ e aumentar sua estabilidade química. Os resultados obtidos nesse trabalho sugerem ainda que se a hidratação das partículas de $\mathrm{MgO}$ for minimizada ou interrompida nos estágios iniciais do processamento (durante a mistura ou as primeiras horas de cura), a espessura da camada de $\mathrm{Mg}(\mathrm{OH})_{2}$ poderia ser reduzida, tornando os efeitos de sua decomposição menos danosos à resistência mecânica e porosidade dos concretos. Esse é o objetivo das novas técnicas anti-hidratação para o MgO em concretos refratários que estão em desenvolvimento no grupo de pesquisa dos autores e serão apresentadas em futuras publicações.

\section{AGRADECIMENTOS}

À FAPESP, Alcoa Alumínio e Magnesita S.A. pelo suporte a esse trabalho.

\section{REFERÊNCIAS}

[1] A. Kitamura, K. Onizuka, K. Tanaka, Taikabutsu Overseas 16, 3 (1995) 3-11.

[2] A. Kaneyasu, S. Yamamoto, A. Yoshida, Taikabutsu Overseas 17, 2 (1996) 21-26.

[3] A. Yoschida, T. Nemoto, A. Kaneyasu, Proc. UNITECR 2003, Osaka (2003) 21-30.

[4] R. Salomão, L. R. M. Bittencourt, V. C. Pandolfelli, Ceram. Int. 33, 5 (2006) 803-810.

[5] R. I. Razouk, R. S. Mikhail, J. Phys. Chem. 62 (1958) 920-925.

[6] G. K. Layden, G. W. Brindley, J. Am. Ceram. Soc. 46, 11 (1963) 518-522.

[7] P. J. Anderson, R. F. Horlock, J. F. Oliver, Trans. Faraday Soc. 61, 516 (1965) 2754-2762.

[8] W. Feitknecht, H. Braum, Helvetica Chim. Acta 50, 7 (1967) 2040- 2053.

[9] P. Brandão, G. E. Golçalvez, A. K. Durate, Refractories Appl. News 3, 2 (1998) 6-9.

[10] P. J. Anderson, R. F. Horlock, Trans. Faraday Soc. 58, 475 (1962) 1993-2004.

[11] R. S. Gordon, W. D. Kingery, J. Am. Ceram. Soc. 49, 12 (1966) 654-660.

[12] V. A. Phillips, H. Opperhauser, J. L. Kolbe, J. Am. Ceram. Soc. 61, 1 (1978) 75-81.

[13] J. Green, J. Mater. Sci. 18 (1983) 637-651.

[14] M. G. Kim, U. Dahmen, A. W. Searcy, J. Am. Ceram. Soc. 70, 3 (1987) 146-154.

[15] M. D. M. Innocentini, F. A. Cardoso, M. M. Akyioshi, V. C. Pandolfelli, J. Am. Ceram. Soc. 86, 7 (2003) 1146-1148.

[16] V. S. S. Birchal, S. D. F. Rocha, V. S. T. Ciminelli, Minerals Eng. 13, 14 (2000) 1629-1633.

[17] S. Chatterji, Cement and Concrete Res. 25, 1 (1995) 51-56.

(Rec. 12/08/2007, Ac. 26/10/2007) 